\title{
In Defence of Logical Nominalism: Reply to Leftow
}

\author{
Richard Swinburne
}

[Swinburne, Richard, 2010, In Defence of Logical Nominalism", Religious Studies, 46, p. 311-30.]

\begin{abstract}
This paper defends (especially in response to Brian Leftow's recent attack) logical nominalism, the thesis that logically necessary truth belongs primarily to sentences and depends solely on the conventions of human language. A sentence is logically necessary (that is, a priori metaphysically necessary) iff its negation entails a contradiction. A sentence is a posteriori metaphysically necessary iff it reduces to a logical necessity when we substitute for rigid designators of objects or properties canonical descriptions of the essential properties of those objects or properties. The truth conditions of necessary se tences are not to be found in any ranscendent reality, such as God's thoughts. 'There is a God' is neither a priori not a posteriori metaphysically necessary; God is necessary in the sense that his existence is not causally contingent on anything else.
\end{abstract}

Most philosophers these days agree that there are token sentences, or propositions (or something else) which token sentences may express, which are necessarily true or necessarily false (as the case may be) with the strongest kind of necessity there is. Most philosophers these days call this strongest kind of necessity 'metaphysical necessity' ${ }^{2}$. It has two species, a priori necessity and a posteriori necessity. The former species, the kind of metaphysical necessity involved in sentences (or whatever) whose status (necessarily true or necessarily false, as the case may be) is discoverable a priori, I shall call 'logical necessity'. Logical nominalism is the thesis that logically necessary truth or falsity (in my sense) belongs primarily to sentences and depends solely on the conventions of human language. This was of course the logical positivist view ${ }^{3}$, but one which has become unfashionable in recent years; and Brian Leftow is one of many who argues that the truth or falsity conditions of necessary and impossible sentences are to be found in some transcendent reality. For most of those who hold this transcendent view of necessary truth, this reality is the eternal truth or falsity of eternal propositions or similar entities, which are either Platonic entities or thoughts had eternally by God. For Leftow the eternal reality which makes logically necessary truths true (and falsehoods false) is God's eternal 'mental events and powers' ${ }^{4}$. In this paper I argue against Leftow and others that we can explain how human language works so as to generate necessary and impossible sentences without the need to make any such 
supposition ; and I draw from my account of human language the consequence that 'There is a God' cannot be a logically necessary sentence.

Although this paper is not primarily concerned with a posteriori metaphysical necessities, I claim that these necessities must be in essence logical necessities; for no other kind of necessity can be as strong as logical necessity. I summarize an account which I have given more fully elsewhere of what their being 'in essence' logical necessities consists $\mathrm{in}^{5}$. This is that an a posteriori metaphysically necessary sentence is one such that when we substitute for rigid designators of objects or properties referred to, 'canonical descriptions' of some of their essential properties (discovered a posteriori), it turns out to be true of logical necessity. (The essential properties of an object or property are the ones logically necessary for the object or property to be that particular object or property. A 'canonical description' of such an object or property is one which picks it out in virtue of its intrinsic nature, e.g. as 'green', and not by some contingent feature, e.g. as 'Amanda's favourite colour'.). When for example we discover that 'Hesperus' rigidly refers to a certain planet composed essentially of a certain chunk of matter, and 'Phosphorus' refers rigidly to a planet composed essentially of that same chunk of matter, and we substitute for 'Hesperus' and 'Phosphorus' in 'Hesperus is Phosphorus' a description of that chunk, the resulting sentence is logically necessary; it has the form ' $\mathrm{a}=\mathrm{a}$ '. Anyone who disagrees with this account of a posteriori metaphysical necessity needs to give a rival one; otherwise it is obscure what is meant by this notion. It does not help to say that a sentence is metaphysically necessary iff it is true in all possible worlds, and so a posteriori necessary if that fact about it can only be discovered a posteriori, since the notion of 'possible world' is also obscure unless defined in a more perspicuous way ${ }^{6}$. What I have written above about necessary truths I mean to apply, mutatis mutandis, to necessary falsehoods. I shall apply my account of a posteriori metaphysical necessity at the end of this paper to argue also against Leftow (as well as many others) - that, not merely can 'There is a God' not be logically necessary, but it cannot be a posteriori metaphysically necessary.

Leftow, largely following Plantinga, uses a somewhat different terminology from mine. He distinguishes 'narrow-logical necessity' from 'broad-logical necessity' ${ }^{\prime}$. He defines 'P is narrow-logically (NL) impossible' (i.e. necessarily false) just if $\mathrm{P}$ entails a contradiction', and ' $\mathrm{P}$ is

necessary' (i.e necessarily true) 'just if $\sim P$ entails a contradiction'. His 'broad-logical necessity' includes both all logical necessities (in my sense of metaphysical necessities discoverable a 
priori) which are not narrow-logical necessities, as well as all metaphysical necessities discoverable only a posteriori. I shall follow my own terminology in this paper, but - when criticizing Leftow - I shall need to comment on the difference of terminologies.

\section{Human Language}

In this main section I show how human language generates necessary and impossible sentences, and how we are able to recognize them. I shall understand by a 'factual sentence' one which is recognized in a language-speaking community as true under a certain range of conditions and false under a certain nonoverlapping range of conditions. We learn which sentences are factual by hearing many examples of them which are treated by speakers and hearers in a certain kind of way. These factual sentences are of various kinds classified by logicians - subjectpredicate, existential generalization, hypothetical etc. Factual sentences are contrasted with sentences having other roles, e.g. performative utterances or questions. Any sentence of any of the same forms as a factual sentence I shall call a 'declarative' sentence. We learn the meanings of different words by seeing the contributions which they make to sentences which include them. More specifically, we learn the meaning of a word by being taught the observable conditions under which sentences in which that word plays a certain role are regarded as true or false, and by the other sentences to which a speaker is regarded as committed by uttering some sentence containing that word in a particular role, and the other sentences which are such that someone who utters them is regarded as committed to a sentence containing that word in a particular role. We learn the meaning of 'lion' for example by seeing the circumstances in which 'there is a lion over there' is regarded as true, and the circumstances in which it is regarded as false; and by the fact that someone who utters this sentence is regarded as committed to 'there is an animal over there', and someone who utters 'there are two lions over there' is regarded as committed to the original sentence. We need to observe different paradigm examples of the observable conditions under which a sentence containing a certain word in various roles is regarded as true or false, and of the commitments speakers who use sentences containing that word in various roles are regarded as having; and this allows us to understand the conditions under which some new sentence containing that word would be regarded as true or false. We extrapolate, that is, from a stock of past examples (of observable conditions and relations of commitment) to an understanding that 
the sentence would be regarded as true (or false, as the case may be) under conditions sufficiently similar to the paradigm examples.

This learning process gives rise to an indeterminacy or vagueness in the truth and falsity conditions of sentences, and so in the public understanding of the meaning of any sentence in three distinct ways. First, there may be border-line cases of conditions 'sufficiently similar to the paradigm examples' of the truthconditions. If someone is taught the truth and falsity conditions of 'this is blue' is by certain examples of blue things contrasted with certain examples of non-blue things (e.g. green things or red things), he will not know whether to say of a certain bluish-green thing whether it is blue or whether it is not blue. Secondly, two speakers taught the meaning of a sentence by the same paradigm examples may have slightly different psychological make-ups as a result of which some of them extrapolate differently from the paradigm examples so as to make different judgments about new examples. And thirdly different speakers learn the truth and falsity conditions of a sentence by being shown slightly different examples of observable conditions under which the sentence is regarded as true or false, and by being given different examples of sentences to which a speaker is regarded as committed by the original sentence and which are such that some one who asserts them is regarded as committed to the original sentence.

Indeterminacy limits inter-personal communication and reasoning; and so dictionary compilers, grammarians, logicians, and other philosophers have sought to lay down rules for correct usage, usually by codifying most people's actual usage. The rules seek to summarize in a few sentences the observable conditions under which various sentences of the language are true and under which observable conditions they are false, and the relations of commitment which sentences have to other sentences. Given a 'correct' use, a sentence then has a public objective meaning, and the distinction emerges between the observable conditions which a particular speaker regards as making a particular sentence true (or false, as the case may be) and the conditions which do in fact make that sentence true (or false); and between the commitments in respect of other sentences which a particular speaker regards himself as having by uttering a particular sentence and those he actually (objectively) has by uttering that sentence. Sometimes 'tidying up' leads to recognition of two distinct senses of an old word. Sometimes it leads to elimination of a minority usage. But the brief rule-stating sentences need to be given content by examples, and insofar as people learn meanings from different paradigm examples for the application and commitments of sentences, and extrapolate from them differently, the indeterminacy will remain. Of course each speaker will believe that he is using words in a way 
which his hearers will understand, and so that he is conforming to any correct usage; but he may not be; and even if he is, that usage may be such that a sentence may be uttered under conditions which lie between its truth-conditions and its falsity conditions.

Which sentences remain vague, and the degree of their vagueness depends on how language is tidied up. But while it is, I suggest, implausible to suppose that it could be tidied up in such a way that no vagueness remains (as the epistemic theory claims to be the actual situation) or so that vagueness is replaced by 'degrees of truth', codification of language in such a way that 'supervaluation' or 'gap' semantics applies is clearly possible, and I cannot understand why Leftow claims (5) that my views rule that out. In such a public language Leftow's ( 4) (DC), 'if the rules commit one to $\mathrm{P}$, it is determinate that they commit him/her to $\mathrm{P}^{\prime}$ will nevertheless hold; and I am puzzled as to why Leftow should think that this constitutes a problem for my view. It is desirable for a public language that there be a fairly precise understanding of the notion of negation; as I shall understand it, the negation of a sentence $s$ is a sentence which has the same truth conditions as $s$ has falsity conditions, and conversely. In philosophical codification of English, ' $\sim s$ ' is often used to designate any device which has this role of negating $s$.

We may call a rule for what one is objectively committed to by a sentence, a rule of mini-entailment. $s_{1}$ mini-entails $s_{2}$ if and only if someone who asserts $s_{1}$ is thereby (in virtue of the rules for the correct use of language) committed to $s_{2} \cdot s_{1}$ entails $s_{\mathrm{n}}$ if they are joined by a chain of mini-entailments, such that $s_{1}$ mini-entails some $s_{2}, s_{2}$ mini-entails some $s_{3}$ and so on until we reach a sentence which mini-entails $s_{n}$. Not all speakers will have been taught the same minientailments of a given sentence; but as long as they have been taught many of the same mini-entailments and have a similar psychological make-up, they may naturally come to assume that the other mini-entailments taught to others also hold. Or, using some mini-entailments, they may be able to derive as derivative entailments what others have been taught as mini-entailments involved in the meaning of the sentence. And if people generally recognize some entailment, it becomes a mini-entailment. If this process of coming to agree about entailments happens fairly quickly and naturally, it becomes natural to say that speakers are just sorting out what is involved in their common concept. They are ensuring that they are using words and sentence-forms in the same more precise senses as each other, but not thereby depriving themselves of a useful sense.

Given a standard 'correct' language, it then becomes apparent that words can be combined into declarative sentences (i.e. 
sentences of one of the same forms as paradigm factual sentences) in such a way that the rules of the language alone suffice to ensure that they cannot be true; and that words can be combined into declarative sentences in such a way that the rules of the language alone suffice to ensure that their negations cannot be true. The former sentences (e.g. 'all squares are round') are the logically impossible sentences, the latter (e.g. 'no squares are round') the logically necessary sentences; they are false or true (as the case may be) 'solely in virtue of the meanings of the words which they contain' and, I must add, 'the way those words are arranged'. There are no circumstances under which the former could be true, and so - it is natural to say - they have no truth conditions (merely falsity conditions). There are no circumstances under which the latter could be false, and so - it is natural to say- they have no falsity conditions $^{8}$. (The 'no circumstances under which they could be' true or false is merely a matter of it following from the rules of language, not a matter of a necessity independent of language.) The paradigm example of a sentence which has no truth-conditions is a selfcontradictory sentence, which is a sentence which claims both that something is so and also that it is not so (normally expressed by a sentence of the form ' $s$ and not $-s$ '.) For such a sentence could only be true if that something was so, and the sentence asserts that it is not so. But it is not, and (despite Leftow's claim in various places) I hope that I have never written in print ${ }^{9}$ that it is, a conventional matter that PNC (the principle of non-contradiction) is true. What arises from linguistic convention is that there are declarative sentences which assert both that something is so and also that that same something is not so, and which sentences they are. Any sentence entailed by a logically necessary sentence will also be logically necessary; for since the former could not be false, neither could any sentence to which (in virtue of the rules of the language) speakers are committed to by it be false. Likewise any sentence which entails a logically impossible sentence will also be logically impossible since if (in virtue of the rules of the language) speakers are committed by some sentence to some other sentence which could not be true, the former sentence itself could not be true.

Logical necessity and possibility are often equated with conceivability and inconceivability ${ }^{10}$. Logically possible sentences are such that it is conceivable that they are true - which we may abbreviate as 'they are conceivable'; logically necessary sentences are such that it is inconceivable that their negations are true-which we may abbreviate as 'their negations are inconceivable'. 'Conceivable' may be used in either an objective or a subjective sense. In the objective sense a sentence is conceivable iff some speaker of the language could understand what it would be like for that sentence to be true, that is could know what are the truth 
conditions of that sentence. 'Understanding what it would be like' for a sentence to be true or 'knowing the truth-conditions' of a sentence are matters of degree, but - whatever the degree involved - both entail the sentence having truth conditions. And since the rules of a language and their consequences are knowable (at least to a considerable extent), it follows that a sentence will be conceivable (in the objective sense) if and only if the rules of the language have the consequence that it has truth-conditions. So the objectively conceivable is the logically possible; the inconceivable is the logically impossible; that, the negation of which is inconceivable, is the logically necessary. In the subjective sense, a sentence is conceivable if some speaker of the language could think that they understood what it would be like to be true in the sense of thinking that they know what its truth conditions are. Subjective conceivability does not guarantee objective conceivability, but it is evidence of it. If it seems to you that you understand what the truth conditions of a sentence are, that is evidence that it does have truth conditions (and the evidence is stronger, the more strongly it seems to you that you do understand this). That follows from the very general principle of credulity that (for any $p$ ) the more strongly it seems to you that $p$, the more probable it is - on your evidence - that $p$. In due course I shall add to this general principle an additional strong reason for supposing that it applies in this case, that the subjectively conceivable is probably objectively conceivable. Henceforward I shall use 'conceivable' in the objective sense.

Leftow's (8) claim that 'once it is determinate what [sentences] say, whether we can conceive what they say is a fact about our powers of conception' is false, if it is read as implying that with different powers of conception we could conceive a given sentence (with a correct meaning in the language) which was previously inconceivable. For what sentences say determines whether or not they are conceivable. Another way of describing the inconceivability of a declarative sentence which I have used is to say that such a sentence lacks ultimate sense; the sentence seems to have a sense, but because of what the rules of language determine is entailed by that sentence, it involves something which it makes no sense to suppose to be true. A declarative sentence which does not involve this then has an ultimate sense. While I agree with Leftow (14) that there are 'individual essences we cannot conceive' (e.g. those of future individuals), no sentence of our language can say anything about such an essence because our language will not have a word which designates that essence. My thesis is a thesis about the inconceivability of sentences of our language, that inconceivability is logically impossibility. In a future language which has a word designating an individual essence currently inconceivable, a sentence about that essence will be conceivable. So Leftow is wrong 
to draw to draw the momentous conclusion that since 'the move from inconceivability in our case to impossibility fails', this 'undercuts Swinburne's whole modal epistemology'.

A sentence is then in Leftow's terminology 'narrow-logically' impossible iff it entails a contradiction and 'narrow-logically' necessary iff its negation entails a contradiction ${ }^{11}$; and that on my account depends on whether there is a sequence of mini-entailments which entail the contradiction. Leftow asserts (1) that I maintain that (in his sense) there are 'only narrow logical necessities', that is there are no broadly-logical necessities. That is not correct. I allow that there are (in my sense) metaphysical necessities discoverable only a posteriori $^{12}$, which are a sub-species of what Leftow calls 'broadly logical necessities'. What I do claim, and what Leftow may have in mind, is that all a priori metaphysical necessities are (in Leftow's sense) narrowly logical necessities (that is, such that their negations entail contradictions), and all a priori metaphysical impossibilities are narrowly logical impossibilities (that is, such that they entail contradictions). To begin with the case of impossibilities - what is asserted could only be a priori impossible if the impossibility is detectable merely by understanding what is involved in what is actually said. To be metaphysically impossible a sentence must have the form of a declarative sentence, in which the component words already have a sense in the language. It will be a subject-predicate sentence, an existential generalization, or some other one of many recognized forms of declarative sentences. It will - to put the point loosely - assert something about some substance or property or event or whatever that it has or does not have some property or relation to some other substance, property etc; or that there are or are not certain substances, properties or whatever. Words have a sense in so far as it is clear what are the criteria for an object, property or whatever being that object, property or whatever - they therefore normally delimit a boundary to the sort of object or property it can be or the sort of properties it can have. Hence it will be inconsistent to affirm that an object picked out by some word is of a kind ruled out by the very criteria for being that object. And the form of a sentence will normally exclude some alternative; and so it will be inconsistent to affirm the sentence together with that alternative. If a sentence is not inconsistent in these ways (or does not entail one that is), we would have no reason to suppose that that sentence is a priori impossible.

It is by its entailing a contradiction (and so being in Leftow's sense 'narrowly logically impossible') that we recognize a sentence to be a priori metaphysically impossible, and by its negation entailing a contradiction that we recognize a sentence as a priori metaphysically necessary. Leftow discusses several examples of sentences which seem to be necessary or impossible truths but 
cannot - he claims- be shown to be so by these criteria. For reasons of space I consider just one such example discussed by Leftow and one discussed by Robert Adams and claim that their accounts of their examples is mistaken. Leftow claims (13), that ' $2=3$ ', which all can agree is logically impossible, does not entail a contradiction. He acknowledges that ' $2 \neq 3$ ' follows from the Peano axiom 'no two natural numbers have the same successor', and the definitions ' $2=1$ 's successor', and ' $3=2$ 's successor'; and yet puzzlingly asserts that the joint negation of the axiom and the definitions 'isn't in the form of a contradiction and doesn't seem to entail any'. But the meanings of ' 2 ' and ' 3 ' are defined by the axiom and definitions which Leftow states; and so not merely do the axiom and definitions entail $(2 \neq 3)$; but $(2 \neq 3)$ entails the axiom and definitions. ' 1 ' wouldn't designate 1 , if it designated a number which could have the same successor as some other number. I don't understand what ' $2 \neq 3$ ' means unless it is such as to mini-entail and to be mini-entailed by ' $\sim(2=3)$ '. So ' $(2=3)$ ' entails a contradiction (' $(2=3)$ and $\sim(2=3)$ ') There was presumably a time when our number talk was a lot less precise than it is now and a lot less useful (we've all heard of the tribes whose number system consists of only three words ' 1 ', '2', and 'many'). But now there is a very clear correct usage defined at least by the above Peano axiom and the stated definitions.

Robert Adams discusses the sentence, 'Everything green has some spatial property', which he claims 'seems to be a necessary truth and yet cannot be shown to be 'analytic'. 13 'Analytic' may be understood in different ways, but one way which he mentions is being true 'solely by virtue of the meanings of its terms'; he claims this account of 'analytic' is 'so vague as to be useless'. I have claimed that spelled out in terms of the negation entailing a contradiction, the notion is clear and is the notion which I have called 'narrowly logically necessary.' I suggest that being 'green' can be understood in two possible ways, but that the cited sentence with 'green' understood in either of these ways can be shown to be logically necessary in my sense. Being green is a property of a thing or substance (in a wide sense). If this thing is a publicly observable thing, then it will exist at a place, and so have a spatial property. Now one might use the word 'green' in such a way that being 'green' entails being a publicly observable thing: to be green is then to have a certain public characteristic. In that case the negation of the cited sentence clearly entails a contradiction. But there is a sense in which a private thing (accessible only to one conscious being), such as a sense-datum (or, less controversially, an after-image) could be 'green'. Clearly what it would be for that private thing to be green is to have the same visual appearance in respect of colour as a green public object. It must look like a surface or a volume which is green; and so must have the visual appearance of a spatial thing. For a 
private object to have the visual appearance of a spatial thing entails it occupying a spatial region of one's visual field. So again, even if one allows private objects, the negation of 'everything green has some spatial property' entails a contradiction.

What goes for these examples goes, I suggest for the general reason stated earlier, for all similar examples. So I stick to my view that it is their relation to contradictions which makes sentences logically impossible or necessary. Hence they have no truth conditions or no falsity conditions, as the case may be; and they are such that they or their negations are inconceivable in the sense analysed above.

What may lie behind the objections of Leftow ${ }^{14}$ and others to my view is the view that all valid proofs must accord with the rule of some recognized system of deductive logic, or consist of a demonstration that there is no model of the proof in which the premises are true and the conclusion is false. But it is an absurd requirement to require a proof to accord with some recognized system of logic. It follows from no logical system that ' $x$ is red' entails ' $x$ is coloured'; and that is a lot more obvious than most entailments. Anyway, such a requirement gets things the wrong way around. Our grounds for believing that some system of logic yields only valid inferences is that it captures as entailments many entailments which we already recognize as such, and none (or almost none) which are clearly not entailments. (Since 'almost none' is vague, it requires a decision to determine that there are so few exceptions that we are justified in calling a system of logic a valid system. Apparent exceptions can then be dealt with by holding that the grammatical form of the sentences involved is misleading as a guide to their 'logical form'.) Our recognition of so many entailments is prior to our recognition of some system of logic as capturing them.

It is equally absurd to require a demonstration of entailment by means of models. For a model is an interpretation of each of the 'non-logical' terms of premises and conclusion; and a demonstration of the validity of the argument consists in showing that there is no model in which the premises are true and the conclusion false. But the validity of a proof so often depends on the 'non-logical' terms involved- no model will show that ' $\mathrm{x}$ is red' entails ' $\mathrm{x}$ is coloured'. (And anyway there is no clear understanding of what counts as a 'non-logical' term.)

Finding for some sentence $s$ a sequence of mini-entailments that shows that that sentence entails a contradiction is however often a very difficult matter; and any particular route of proof may be challenged by someone disputing some purported mini-entailment from some $p$ to $q$ along the sequence. An opponent will challenge a claim that $p$ mini-entails $q$ by claiming that $q$ is not something to 
which anyone is committed when using $p$ in the correct sense. This disagreement may be overcome if the proponent can get his opponent to recognize some $r$ such that $p$ mini-entails $r$ and $r$ minientails $q$. Or the disagreement may be bypassed if the proponent can find a different sequence of mini-entailments from $s$ to $a$ contradiction which an opponent will recognize as such.

There is a way of attempting to prove that a sentence $s$ is not logically necessary or (as the case may be) not logically impossible (other than by proving that it is impossible, or as the case may be, necessary), which involves an extra step. This involves showing that $s$ or (as the case may be) not-s is logically possible (i.e. does not entail a contradiction). For if not-s is logically possible, then $s$ is not logically necessary; and if $s$ is logically possible, then not-s is not logically necessary. The extra step involves finding a sentence $r$ which disputants agree to be logically possible. The argument then consists in showing that $r$ entails $s$ (or, as the case may be, not-s) by a sequence of agreed mini-entailments. For if $r$ does not entail a contradiction, neither does any sentence entailed by it. So if disputants can agree that $r$ is a logically possible sentence and that $r$ entails $s$, they can agree that $s$ is not logically impossible. Philosophers often try to show that some supposition - for example 'there are two spaces', a space being a system of places each of which is at some distance in some direction from each other place of the system and from no other places - is logically possible, by describing in detail a situation under which it would be true. That is, they claim that the latter description entails that there are two spaces; and that since the latter description is logically possible, 'there are two spaces' is also logically possible. But the same problems about recognising entailments may arise, as before; and there is the additional need to secure agreement that $r$, which will typically be quite a long conjunction, is logically possible. But again if disputants cannot agree that some suggested starting point is logically possible or that certain mini-entailments hold, they may be able to find a different starting point with a different route of proof on which they can agree.

Yet long failure to agree on a sequence of mini-entailments and (if required) a logically possible starting-point which shows a sentence $s$ to be or not to be logically necessary or impossible (as the case may be), may show that the disputants are using words in different senses. One or other disputant may be using words in ways importantly different from the correct way, or there may be no one correct way. But when each of the two disputants is prepared to recognize that the other disputant is using words in a legitimate way, that is that their use has been introduced by paradigm examples and inferential rules such that some sentences containing those words used in the different sense have ultimate sense (i.e. do not entail 
contradictions arising from the senses of those words), then there is no substantial dispute between them. For example some writers have been introduced to the phase 'epistemically justified' by (among other paradigm examples) examples such as that a clairvoyant whose beliefs were produced by a reliable process is epistemically justified in holding them, and that if we had the same set of beliefs about the external world in an evil-demon world as we do now we would not be justified in holding them. These examples lead to a reliabilist epistemology in which a belief being 'justified' entails that it is produced by a reliable process. But other writers have been introduced to this phrase by many paradigm examples of people holding beliefs, including false beliefs, which in some a priori sense are made probable by the evidence accessible to them - which leads to an internalist epistemology of epistemic justification in which the justification of a belief depends solely on introspectible data, and does not entail that the belief is produced by a reliable process. But epistemologists are beginning to recognize that both senses of 'epistemic justification' are legitimate senses. ${ }^{15}$

However the dispute is more serious when one or other disputant is not prepared to recognize the other's usage as legitimate. The disputants could have been introduced to a word by somewhat different paradigm examples and mini-entailments. But they could have been introduced to the word by exactly the same paradigm examples and exactly the same set of mini-entailments, but extrapolate from them differently so as to produce the disputed minientailments. The longer the dispute lasts and proves insoluble by the attempts of one disputant to get the other to recognize the minientailments or initial starting points which he acknowledges, or to agree that they are each using words in different legitimate senses, the more probable it is that one or other disputant is suffering from an intellectual deficiency. This deficiency will be either that one disputant cannot recognize a further property manifest in the paradigm examples of the application of the word and its agreed mini-entailments, not logically equivalent to the one which both of them can recognize, or that one disputant is deceiving himself when he claims to recognize such a property.

Thus most of us have been taught the meaning of the word 'person' by examples of the same kind ('John is a person', 'you are a person', 'this is the same person as the person you saw last week') and similar mini-entailments ('John is a person' mini-entails 'John is sometimes conscious', and is mini-entailed by 'John is human'.) But we may recognize more than one similar property in the common paradigm examples, consistent with the paradigm mini-entailments. We will all recognize the paradigm examples as examples of spaceoccupying and sometimes conscious animate beings with a certain sophistication of thought. We will all also recognize the paradigm 
examples as examples of sometimes conscious animate beings with a certain sophistication of thought. We can all agree that 'person' can be defined either as a being of the former kind or as a being of the latter kind. But some of us will think that someone being a person on either definition mini-entails their being a person on the other definition; while others of us will think that the two definitions pick out different properties, possession of the former mini-entailing possession of the latter but not conversely, and then prefer to define being a 'person' as being a being of the latter kind. Consequently the first group will hold that 'this person will exist tomorrow without occupying space' (i.e. in a disembodied state) is logically impossible, whereas the second group will allow this as a logical possibility. The first group will hold that the second group in claiming to have a sense of 'person' not logically equivalent to the former sense do not have a legitimate sense of 'person', and are deceiving themselves in thinking that they do. The second group, while acknowledging that the first group have a legitimate sense of 'person' (though not their preferred sense) claim that their latter sense is also a legitimate sense; they can see a property common to the paradigm examples exemplifiable without the feature of space-occupying. This disagreement will be difficult to resolve in the ways which I have been describing earlier of finding common starting-points or sequences of mini-entailments, and it may prove irresoluble.

A strong reason however why we can suppose that normally these methods will reach clear and agreed results is because we are investigating the meaning (as given by observable truth-conditions and mini-entailments) of sentences of a human language, to the rules of which we have been introduced by very similar training. We are very similar to each other in our psychological make-up; and so we would expect normally to agree with each other about the minientailments of sentences and so about which sentences are logically necessary (or impossible). It is only when some of us are blind to certain differences between properties or self-deceived, that this won't happen. And while for any sentence whatever what seems to be true is - on that evidence - to some extent probably so (which is the claim of the principle of credulity), we have in this case a further consideration that increases the probability that most of our judgements about mini-entailments and so about logical necessity or impossibility are true. This consideration is that our judgements concern features of our own human language, and we know our way about our own language. Evidence that we are well equipped and placed to make correct judgements about some matter increases the probability that the judgements we make are true. This fact about the nature of our judgements about these matters reinforces the probability that in general (when there is not significant disagreement) what seems logically possible, very probably is 
logically possible; and similarly for the necessary and impossible.

My conclusion from this long section is that logical necessity (and impossibility) and our access to it can be explained fully by the linguistic conventions governing sentences. Of course that is not to deny that God knows all necessary truths, in the sense that he knows at all times that if humans were to speak a certain language which sentences of that language would be necessarily true; nor is it to deny that God is the source of the ability of humans to speak whatever languages they speak.

\section{The Transcendent World}

But many philosophers, among them Brian Leftow, believe that there is a much deeper realm of reality than the mundane realm of human sentences which I have described, on which necessary truth ultimately depends. This view acknowledges that humans may not always understand the truth-conditions of sentences in the same way as each other and may disagree about whether some sentence entails another one. But on this view fortunately there are languageless things which constitute the truth and falsity conditions of necessary or impossible human sentences ${ }^{16}$. I will discuss this view initially in terms of the variant that such sentences express eternally true or false 'propositions' which exist in a Platonic heaven, then I will apply my results briefly to the variant that these propositions are thoughts in the mind of a necessarily existing $\operatorname{God}^{17}$, and finally come to Leftow's own variant of what is the locus of the truth and falsity conditions of necessary and impossible sentences.

Before going further I need to draw attention to different languageless entities which may be described as 'propositions'. Lemmon $^{18}$ distinguishes between what he calls a 'proposition' (which in order to avoid confusion with a wider sense of 'proposition' I shall call 'L-proposition', and what he calls a 'statement'. The Lproposition which a token sentence $s$ expresses is that element of claim in what is said which would also be made by any other token sentence which is synonymous with $s$. Two sentences express the same L-proposition' if and only if they are synonymous. 'Rex mortuus est' uttered by a Latin speaker of the fourteenth century, 'Le roi est mort' uttered by a French speaker of the eighteenth century, and 'The king is dead' uttered by an English speaker of the twentieth century would then (on normal understandings of their meanings) express the same L-proposition. A L-proposition' plus its context of utterance determines which statement is made. A statement (as 
Lemmon understands it) is that element of claim in what is said which concerns the actual individuals, properties, times, places etc picked out by the referring expressions, independently of how they are picked out. The three token sentences just cited did not express the same statement, for (we may reasonably suppose) they concern different kings. Whereas 'I am ill' spoken of me, 'you are ill' addressed to me, and 'he is ill' spoken of me, do all express the same statement (although not the same L-proposition.) . A L-proposition and a statement are both to be distinguished from the 'thought' (in what I take to be Frege's sense) which a token sentence $s$ expresses, which is that element of claim made by any other token sentence which expresses both the same L-proposition and the same statement as $s$. Those token sentences whose truth-value does not depend on any non-linguistic conditions including those which determine the reference of their referring expressions, express logically necessary or logically impossible L-propositions and thoughts. Those sentences which, given the actual objects or properties picked out by their referring expressions (e.g given the planet actually picked out by 'Hesperus'), have a truth-value independent of all other non-linguistic conditions express a posteriori metaphysically necessary or impossible statements and thoughts. Thus given (and only given) the actual reference of the referring expressions in the sentence 'Hesperus is Phosphorus' (which is that both 'Hesperus' and Phosphorus' refer to a planet formed of the same chunk of matter), that sentence expresses a necessary statement and a necessary thought.

Now certainly it is useful in various philosophical contexts to talk as if there were such entities as these. For example, if we want to talk about a claim made by some sentence, and we want what we say to apply to the claim made by any other sentence which attributes the same properties to the same objects at the same time, it is more convenient to talk about the claim made by the statement expressed. But the Platonist claims that L-propositions and/or statements and/or thoughts really exist in a Platonic heaven, marked with their logical status (e.g. 'logically necessary') whether or not any human language does or could express them. Having made the distinctions between L-propositions, 'statements' etc in order to bring out the different languageless things which might be supposed to be expressed by sentences, I shall in future ignore them and make my points merely about 'propositions', understood as covering all or any of these.

Yet, as I have illustrated, we can analyse metaphysical necessity and impossibility in terms of token sentences, the circumstances under which speakers would regard them as true (false), and the commitments to other sentences which speakers are considered to have when they utter those sentences. Why postulate 
more? One answer sometimes given is that propositions would explain why speakers behave as they do. Speakers have some grasp of this eternal web of propositions; they seek to express propositions in language and to conform in their human inferences with human sentences to the entailments of eternal propositions. But there's an easy explanation of human linguistic behaviour which involves no such apparatus. Humans want to know what the world is like for theoretical and practical reasons; and to communicate information about this to others and receive it from others. For this purpose they need sentences with fairly clear content. The content of a sentence will only be clear to the extent to which the sentence has sharp truth and falsity conditions. Hence the need for agreement about paradigm examples and mini-entailments. The existence or nonexistence of propositions wouldn't make this behaviour any more or less comprehensible. Further, if the necessity of propositions depended on some transcendent non-linguistic fact, there would be no additional good reason (other than that provided by the principle of credulity) to suppose that we would be able to recognize that necessity. Our access to how human language works is better than our access to the transcendent, and so our 'intuitions' about the former are more to be trusted than our intuitions about the latter. To suppose that there are propositions would involve supposing that we know less about necessary truths than surely we do. All told, there are no grounds for postulating the existence of propositions as Platonic entities.

But theism opens the way to variants of a transcendent world view which make necessary truths and impossibilities, not independent entities, but ones grounded in the activity or nature of a God to which theism is already committed. One variant is that propositions are God's thoughts, necessary propositions being the ones which he (in some sense) necessarily thinks and whose necessity depends on God thinking them. Brian Leftow's variant avoids postulating propositions by holding that the truth makers of necessary truths are 'ultimately divine mental events and powers', divine events being 'understood in a broadly functionalist' way ${ }^{19}$. Then what makes a token sentence 'no squares are round' necessarily true is that God's nature makes it the case that whoever utters such a sentence utters a true sentence. A theist holds that all existent things and their properties depend on God as the necessary condition (and except insofar as the free will of creatures is also involved, the sufficient condition) of their existence; and so if a theist also holds that necessary truths have transcendent truthconditions, he will want to locate these truth-conditions in God in some such way. But it is a natural reaction to any such theory to say that surely 'no squares are round' is true whether or not God thinks it or has the appropriate mental state. And if the truth of 'no squares 
are round' is just the truth of a human sentence whose truth results from human conventions, there is no need for a theist to deny that. For given that there is a God, it will be because of God's creative act that humans exist and establish linguistic conventions and so utter sentences which are necessarily true (or false). It remains the case that there is no reason to postulate transcendent truth-conditions for necessary and impossible truths.

\section{God's necessity}

Quite a number of religious thinkers since Anselm have thought of God as a logically necessary being, and in his paper Leftow gives a tentative argument in favour of this view (in his terminology a tentative argument to show that God's existence is 'narrow-logically necessary'.) Given the results of the first section of this paper, God would be a logically necessary being if and only if the sentence 'There is no God' entails a contradiction. Those who put forward an ontological argument have attempted to prove that there is a God by claiming that 'There is no God' does entail a contradiction. But notoriously, ontological arguments are either invalid or have a highly dubious premise (e.g. Leftow's (15) 'Necessarily if God exists, he exists necessarily'). Another example of a similarily dubious premise is the premise in the ontological argument put forward by Plantinga, "There is a possible world in which maximal greatness is instantiated'. Plantinga defines a being as having 'the maximal degree of greatness in a given world $\mathrm{W}$ only if it has maximal excellence in every possible world. Maximal excellence entails omnipotence, omniscience, and moral perfection. ${ }^{20}$ The apparently modest premise then yields the strong conclusion that there actually exists a maximally great being. An advocate of an ontological argument may attempt to show that the premiss deemed dubious by others is a necessary truth by deriving a contradiction from its negation by means of mini-entailments, but few doubters are likely to be convinced by the attempt. But there is a very powerful argument for the logical possibility of 'There is no God' from the strong a priori obviousness that some descriptions of a godless world do not entail a contradiction. Surely there is no contradiction entailed by the existence of a world in which there are just four atoms not caused to begin or to continue to exist by anything or anyone else. Spelling out what it would be like for this suggested world or some other similar uncaused physical world to exist will surely in the course of time get almost anyone to admit that there is no contradiction entailed by the existence of one such world. The existence of such a world entails the non-existence of God, the supposed cause of the existence of all 
substances. It follows from the logical possibility of such a world that 'there is no God' is logically possible and so (given S5) that it is logically necessary that it is not logically necessary that there is a God. So not merely is the dubious premise of a typical ontological argument false, but necessarily if there is a God, his existence is logically contingent.

But why should not 'there is a God', read as 'God exists' where 'God' is a rigid designator of an individual whose essential properties we do not know, be a posteriori metaphysically necessary, in Leftow's terminology a posteriori 'broadly logically necessary'? Leftow claims that this is so, as have many others in recent years. Given my claim at the beginning of the paper that a sentence is a posteriori metaphysically necessary iff it reduces to an a priori necessity by substitution of canonical descriptions of some essential properties of the properties or objects rigidly designated, it follows that 'God exists' would be a posteriori metaphysically necessary iff it reduces to an a priori necessity when we substitute for 'God' some canonical descriptions of his essential properties. Even if we did not know any of the essential properties of God, any theist must hold that (if there is a God) the actual properties of God include being an all-powerful and all-good cause of the world. Hence the existence of a world with four uncaused atoms (or any similar supposition) entails the nonexistence of any being with any essential properties at all (however described) who has the actual properties of being an all-powerful and all-good creator. And so the logical possibility of the fouruncaused-atoms world (or any similar world) entails the logical impossibility of a (either a posteriori or a priori) metaphysically necessary God. So I do not need such a precise thesis of the necessary and sufficient conditions of a posteriori necessity as that stated at the beginning of this paper in order to get this result.

But if there were to be logically necessary eternal propositions, and especially ones whose necessity does not arise from their negation entailing a contradiction, or sentences which have their truth-conditions in aspects of the divine nature, then it seems prima facie coherent to suppose that some sentence somewhat similar to Leftow's (15) might be or expresses one of these. Maybe there is a proposition which (15) expresses which is logically necessary (or a divine mental event which makes (15) logically necessary) without the proposition or sentence entailing a contradiction. And if one thinks that there could be propositions or sentences which are a posteriori metaphysically necessary for reasons other than that those sentences or the sentences which express the propositions express a priori necessities when canonical descriptions of some essential properties are substituted for rigid designators, maybe 'God exists' could be or express an a posteriori necessary truth. It's one person's intuition against another person's intuition; further argument does 
not seem possible.

We shall however only be in this situation of a clash of irresoluble intuitions, if we start postulating strange metaphysical entities or find truth conditions in apparently irrelevant places for no good reason. If it is only human conventions which make sentences necessarily true or false, it is not likely that we shall be very often in the situation of a clash of irresoluble intuitions about what are the metaphysically necessary truths. We may however, as we saw earlier, occasionally be in this situation because some people extrapolate from the teaching process in ways which other people cannot understand, or mistakenly think that they are extrapolating in a way which yields a legitimate sense. But because we all have a similar psychological make-up and belong to a language-community, that will not happen often. And for reasons given earlier, it is plausible to suppose that almost everyone can eventually come by the method described earlier to see that 'there is a God' is not a logically necessary sentence. That is not to deny that God is a necessary being in the sense which all theists would endorse that his existence is not causally contingent on anything else (i.e. nothing else causes him to exist).

\section{NOTES}

1.I defend here a view advocated in chapter 5 of my book The Christian God (Oxford:Clarendon Press, 1994) against criticisms made by (among others) Brian Leftow in a paper 'Swinburne on Divine Necessity', Religious Studies, forthcoming. Many thanks to Brian Leftow for very helpful comments on an earlier draft of this paper.

2.'We can agree with Frank Jackson, David Chalmers, Saul Kripke, David Lewis [and many others] .. that metaphysical necessity is necessity in the widest sense' - Robert Stalmaker Ways a World might be (Oxford: Clarendon Press, 2003), 203.

3. 'The truths of logic and mathematics are analytic propositions or tautologies' and 'a proposition is analytic when its validity depends solely on the definitions of the symbols it contains' - A.J.Ayer Language, Truth, and Logic (London: Victor Gollancz, $2^{\text {nd }}$ ed.,1946), 77, 78. By 'validity' he surely means in more precise terminology 'truth-value'.

4.Private correspondence, where he adds that he is 'broadly functionalist on [the divine events involved]'. Leftow's view of what makes necessary sentences true is developed at length in his forthcoming book on Necessity. 
5. For my account of a posteriori metaphysical necessity see section I of my 'From mental/physical Identity to substance dualism' in (ed.) P. van Inwagen and D.Zimmerman Persons, Human and Divine, (Oxford: Clarendon Press, 2007). I give there a more precise definition of what I have called here a 'canonical description' and call there an 'informative designator'.

6.In their Introduction to their collection Conceivability and Possibility (Oxford: Oxford University Press, 2002), 4, T.Gendler and J.Hawthorne write that the notion of metaphysical possibility is standardly taken to be primitive', adding in a footnote 'in contemporary discussions at any rate.' They explain (p.5) that 'metaphysical possibility is more expansive than nomological possibility, less expansive than narrow logical possibility.' But we need more clarification than that in order to have a useful notion with which to operate.

7.Leftow identifies his distinction between broad and narrow logical modality with distinctions made by both Plantinga and Kripke (Leftow 1, n.2 and n.42). But for Plantinga, narrow logical necessity includes only 'truths of propositional logic and first-order quantification theory'. See his The Nature of Necessity (Oxford:Clarendon Press, 1974, 1-2. Broad logical necessity seems however for Plantinga, as for Leftow, to include all metaphysical necessity (in my sense), other than narrow logical necessity. Kripke does not, as far as I know, use the terms 'narrowly' and 'broadly' 'logically necessary', but distinguishes between a priori and a posteriori necessity and (what I think amounts to the same distinction) between de dicto and de re necessity. See his Naming and Necessity (Oxford:Blackwell Publishing, 1982) passim.

8.Leftow's (10) account of 'absolute necessity' as necessity 'given the truth of a null set of sentences' seems to me to apply only to logical necessity. I suggest that metaphysical non-logical (that is, a posteriori ) necessity is best understood as differing from this in being relative to the existence of certain objects, e.g. 'Hesperus is Phosphorus' is necessary given that Hesperus exists.

9.Leftow cites (15) an unfortunate sentence of mine in private correspondence wrongly suggesting that it is against the rules to let a contradictory sentence count as true only 'when doing logic'. I certainly hold that no contradictory sentence can ever be true. But my point is that some sentences which have the form ' $p$ and not $-p$ ' do not express contradictions. For example, 'it is and it isn't raining' may be used to describe the situation where there are just a few spots of rain falling.

10.Hume (if we read his 'imagine' as 'conceive') Hume states a weaker relation between these concepts: "tis an established maxim in metaphysics, that whatever the mind clearly conceives includes 
the idea of possible existence, or in other words, nothing we imagine is absolutely impossible.'- Treatise of Human Nature 1.2.2.

11. This understanding of necessity which he sometimes calls 'metaphysical necessity' is that of Leibniz. Thus he writes of 'a necessity which takes place because the opposite implies a contradiction (which necessity is called logical, metaphysical, or mathematical)' - (ed.) H.G. Alexander The Leibniz - Clarke Correspondence (Manchester: Manchester University Press, 1956) Leibniz's fifth paper, para. 4. Leibniz thinks however (see note 17 below) that this necessity arises ultimately from God necessarily thinking the thoughts which have this character.

\section{See for example The Christian God, 112}

13.See Robert Adams's article 'Divine Necessity' republished in his The Virtue of Faith (Oxford:Oxford University Press, 1987) 213-4.

14. My reason for suggesting that this is what lies behind Leftow's view that there can be logically necessary truths, the negations of which do not entail contradictions is that in discussing (his 11) my attempt to prove the necessity of 'nothing can be red and green all over', he asserts that I cannot 'simply insist' 'that something entailed by being the one colour contradicts something entailed by being the other', I 'must show' it. And showing it, he claims, involves the argument having a certain form. But, I am suggesting that there is no way of proving an unrecognized entailment except by appealing to recognized entailments (although, I grant, the form of an argument may help us to recognize an entailment). I was trying to appeal to an entailment which almost everyone would recognize. But if I have an opponent who doesn't recognize it, that doesn't mean that I haven't proved the contradiction; it only means that my opponent can't recognize that I've proved the contradiction. Some of the disagreement about this example may arise from a misunderstanding about what 'nothing can be red and green all over' is supposed to mean. I am understanding 'red' as 'pure red' and 'green' as 'pure green'. So I am not claiming that it is a 'narrow logical' necessity that there cannot be reddish-green surfaces. It does however seem to be a feature of our colour-detecting mechanisms that surfaces do not normally look reddish-green; and since the colour of things is the way they normally look, surfaces are not normally reddish-green. Leftow's reference to C.L.Hardin , Color for Philosophers (Indianapolis:Hackett, 1988) 124-6 suggests that he may have understood the disputed sentence in a different way from myself.

15.See William Alston, Beyond 'Justification' (Ithaca, N.Y: Cornell University Press, 2005) 26: 'The parties to at least the most radical of the disputes about epistemic justification are using "justified" to pick out different properties of beliefs.. They differ more strongly 
than disagreeing about a common object; they are talking about different things under the label "justified" '.

16. If (as Leftow(5) claims) 'there are widespread intuitions that entailment is not a vague concept', these must be philosophers' intuitions about propositions. It seems totally implausible to suppose that the entailments of sentences of ordinary language are never vague, as my discussion of 'epistemically justified' illustrates. Leftow must be claiming that vagueness about whether one sentence entails another consists in indeterminacy about which proposition (with totally determinate entailments) is expressed by the former sentence.

17. "The understanding of God is the region of eternal truths and of the ideas on which they depend, and .. without Him there would be nothing real in the possibilities- not only nothing existent, but also nothing possible...Necessary truths depend solely on [God's] understanding of which they are the internal object.' -G. W. Leibniz, Monadology, (tr. Mary Morris Leibniz's Philosophical Writings (London: J.M.Dent and sons, 1934) sections 43 and 46. For a modern statement of this view see T.V. Morris and C.Menzel, 'Absolute Creation', American Philosophical Quarterly, 23(1986), 353-62.

18.E.J. Lemmon, 'Sentences, Statements, and Propositions' in (ed.) B. Williams and A. Montefiore British Analytical Philosophy (London: Routledge and Kegan Paul, 1966).

19. I am citing private correspondence with Leftow - see note 4 above.

20. Alvin Plantinga, God, Freedom, and Evil (London:George Allen and Unwin, 1974) 111, 108. 